\title{
Phthalocyanines and porphyrins linked to gold adatoms and their catalytic property towards hydroxide oxidation
}

\author{
Karolien De Wael*, Annemie Adriaens \\ Ghent University, Department of Analytical Chemistry, Krijgslaan 281 S12, B-9000 Ghent, Belgium
}

Received 7 August 2007; received in revised form 21 September 2007; accepted 26 September 2007

Available online 2 October 2007

\begin{abstract}
This paper describes the electrochemical formation and detection of gold adatoms, by recording successive cyclic voltammograms of a gold electrode in base, and their ability to function as an anchor for phthalocyanine or porphyrin adsorption. The values of the redox potential of the adatom reactions are linked to the redox potential of the adsorbed central metal ion, cobalt or copper, of the phthalocyanine or porphyrin compound. In addition, when using a phthalocyanine or porphyrin immobilized on a gold electrode, the detection of hydroxide can be improved by electrocatalysis. The catalytic current was found to vary linearly with the hydroxide concentration and a detection limit of $11 \times 10^{-6}$ mol $\mathrm{L}^{-1}$ for a 5,10,15,20-tetrakis-(4-carboxyphenyl)-porphyrin-Co(II) modified gold electrode could be calculated.
\end{abstract}

(C) 2007 Elsevier Ltd. All rights reserved.

Keywords: Electrocatalysis; Phthalocyanines; Porphyrins; Adatoms; Hydroxide

\section{Introduction}

The metastable state of metals is well known in metallurgy $[1,2]$, but largely ignored in surface electrochemistry. Adatoms are so-called metastable, active (or low lattice coordination state) surface metal atoms, such as terrace, step, ledge and kink atoms [3-6]. It has been pointed out that some metals, e.g. gold [7], undergo a premonolayer oxidation in which these adatoms are oxidized at potentials well below the potential required for regular monolayer $\alpha$-oxide formation. Gold adatoms give thus rise to faraday currents in the premonolayer region; they undergo oxidation to yield low-coverage hydrous oxide species that can mediate oxidation and reduction processes at the electrode surface. Therefore, these species can play an important role in electrocatalytic reactions [7-10]. Next to the classical ways to obtain a certain number of adatoms, there are several alternative procedures to gain metastable species, including gas deposition, laser treatment, ion sputtering and potential cycling $[1,2]$. The latter involves a surface roughening. As will be presented in this article, this roughening step is also needed to immobilize macro-

\footnotetext{
* Corresponding author at: Postdoctoral Fellow of the Research Foundation, Flanders, Belgium. Tel.: +32 926448 20; fax: +32 92644960 .

E-mail address: Karolien.DeWael@UGent.be (K. De Wael).
}

cyclic compounds, such as tetrapyrroles. Here, phthalocyanines and porphyrins were selected as tetrapyrroles. The former have been widely used as dyestuffs and colours. Nowadays they are also commonly used in high-tech applications, such as photovoltaic, electronic and sensing devices [11-14]. Porphyrins are widespread compounds in nature. They are important for several mechanisms in life: they catalyse enzymatic reactions and are, for instance, responsible for the oxygen transport in the human body [15]. The major characteristics of the phthalocyanine and porphyrin macrocycle are their thermal and chemical stability, coupled with their extensive redox chemistry. The aromatic ring structure can be electrochemically oxidized and/or reduced [11]. More than 70 different metal ions can form a complex by coordinating with the ring. When the central metal is a transition metal, its ion can also be electrochemically active. The immobilization of these compounds on an electrode surface can lead to modified electrodes with electrocatalytic properties. As a result, the charge transfer kinetics of the oxidation or reduction of some molecules, e.g. sodium dithionite, can be increased by modifying bare electrodes by phthalocyanines or porphyrins [16]. Electrodeposition is the method used in this study to deposit a film of phthalocyanine or porphyrin onto a gold electrode. A continuous potential cycling of the electrode between two potentials in a phthalocyanine or porphyrin solution can lead to a modification of a bare electrode in a very reproducible way [17]. By 
measuring the current, it is possible to follow the adsorption process in situ.

This paper describes the electrochemical formation and detection of gold adatoms by recording successive cyclic voltammograms of a gold electrode in base and their ability to function as an anchor for phthalocyanine or porphyrin adsorption. The authors will also show that the detection of hydroxide on bare gold electrodes can be improved by electrocatalysis using a phthalocyanine or porphyrin as catalyst.

\section{Experimental}

A saturated calomel electrode with two compartments (SCE, Radiometer, Copenhagen) and a carbon stick were used as the reference and counter electrode. The working electrodes were gold electrodes from BAS (West Lafayette, USA) (diameter $1.6 \mathrm{~mm}$ ) and were pretreated by mechanical and electrochemical polishing. Before its first use, the electrode surface was scoured briefly on 1200 grit SiC-emery paper to obtain a fresh surface. To smoothen this relatively rough surface, it was further subjected to sequential polishing on a polishing cloth covered with alumina (Buehler, Illinois, USA) powder of $1,0.3$ and $0.05 \mu \mathrm{m}$ particle size for respectively 5, 10 and $20 \mathrm{~min}$. To remove any adherent $\mathrm{Al}_{2} \mathrm{O}_{3}$ particles, the electrode surface was rinsed thoroughly with doubly deionised water and cleaned in an ultrasonic bath (Branson 3210) for 2 min. Finally, the electrode was pretreated electrochemically by scanning it in a $\mathrm{Na}_{2} \mathrm{HPO}_{4} / \mathrm{NaOH}$ buffer solution ( $\mathrm{pH}$ 12, purchased from Riedel-de Haën) between -1.2 and $0.6 \mathrm{~V}$ versus SCE until five subsequent scans were identical. The scan rate for all cyclic voltammetric experiments was $50 \mathrm{mV} \mathrm{s}^{-1}$. Before each experiment, pure nitrogen was bubbled through the cell solution for $20 \mathrm{~min}$.

A PGSTAT20 potentiostat (ECO Chemie, The Netherlands) controlled by GPES 4.9 software package running on a Pentium II computer (Eknadata) was used to perform the potential cycling and to obtain the voltammetric data. Measurement of the $\mathrm{pH}$ of the solution was done using a Model 420A Orion Benchtop pH-meter. The phthalocyanine compounds, more specific $3,4^{\prime}, 4^{\prime \prime}, 4^{\prime \prime \prime} \mathrm{Cu}(\mathrm{II})$ tetrasulphonated phthalocyanine sodium salt (CuTSPc) and Co(II)tetrasulphonated phthalocyanine sodium salt (CoTSPc) were purchased respectively from Sigma Aldrich (USA) and Rhodes University of Grahamstown, Eastern Cape (South Africa). The porphyrin compounds were purchased from Porphyrin Systems (Lübeck, Germany): 5,10,15,20-tetrakis-(4-carboxyphenyl)-porphyrin-Cu(II) (CuTCPor), 5,10,15,20-tetrakis-(4-carboxyphenyl)-porphyrin-Co(II) (CoTCPor), 5,10,15,20-tetrakis(4-sulphonatophenyl)porphyrin-Co(II) tetrasodium salt (CoTSPor). Sodium hydroxide $(\mathrm{NaOH})$ and sodium sulphate $\left(\mathrm{Na}_{2} \mathrm{SO}_{4}\right)$ were purchased from Sigma Aldrich (USA).

Electrode modification was performed by recording successive cyclic voltammetric scans (60 scans) in a potential window from -1.2 to $0.6 \mathrm{~V}$ versus $\mathrm{SCE}$ in a $\mathrm{Na}_{2} \mathrm{HPO}_{4} / \mathrm{NaOH} \mathrm{pH} 12$ buffer solution containing $1 \times 10^{-3} \mathrm{~mol} \mathrm{~L}^{-1}$ phthalocyanine or porphyrin. An analogous experiment was done in the same $\mathrm{pH}$ 12 buffer solution not containing phthalocyanine or porphyrin to investigate the formation of adatoms at a gold electrode.

\section{Results and discussion}

\subsection{Electrochemical detection of gold adatoms}

It was already suggested in the introduction that by repetitive cycling in a potential window the amount of adatoms at a gold electrode increases. To investigate this statement, a gold electrode was subjected to successive cyclic voltammetry in a pH 12 buffer solution. Fig. 1 represents a selection of the 5000 cyclic voltammetric scans recorded at a bare gold electrode from -1.2 to $0.6 \mathrm{~V}$ versus SCE with a scan rate of $50 \mathrm{mV} \mathrm{s}^{-1}$. The peaks corresponding to the oxidation of the gold surface $\left(A_{\mathrm{a}}\right)$ and the reduction of the gold $\alpha$-oxide formed during surface oxidation $\left(A_{\mathrm{c}}\right)$ decrease with growing scan number $[7,8,18,19]$. In contrast, the current of the redox couples $\mathrm{B}$ and $\mathrm{C}$ grows during the potential cycling experiment. A literature study [7-9,18,20] revealed that these pairs of peaks are attributed to gold surface reactions of so-called adatoms ( $\mathrm{Au}^{*}$ ) and their corresponding $\mathrm{Au}(\mathrm{III})$ incipient hydrous oxides. The more reactive adatoms (those of lowest lattice coordination number) oxidize first, the less active oxidize later, at more anodic potentials. These species have unique properties as they do not belong to the crystallographic structure; they are assumed to take place mainly at different defect sites on the electrode, including steps, grain boundaries or terraces. Therefore, the reactivity of adatoms depends on its nature. It is clear that at scan 5000 the sum of the charges of all six processes equals the sum of the charges of peak $A_{\mathrm{a}}$ and $A_{\mathrm{c}}$ in scan 10 . This illustrates that the redox processes $\mathrm{B}$ and $\mathrm{C}$ originate from the gold $\alpha$-oxide process $\mathrm{A}$. A prerequisite to observe those adatom peaks is that the potential cycling includes the $\alpha$-oxide potential region, more specific $0.3-0.6 \mathrm{~V}$ versus $\mathrm{SCE}$, in order to roughen the gold surface and create surface defects and thus adatoms which are possible 'anchors' for other molecules. This effect is also called the place-exchange phenomenon [20]. When the repetitive cycling is performed in the potential region from -1.2 until 0.2 V versus SCE (just before $\alpha$-oxide formation), none of the adatom peaks appear.

\subsection{Adatoms as anchors for phthalocyanine or porphyrin adsorption}

Running through this roughening procedure $(0.3-0.6 \mathrm{~V}$ versus SCE) is also a necessity to deposit phthalocyanines or porphyrins onto a gold electrode. As the authors have shown previously, these compounds can be immobilized onto electrodes by recording successive cyclic voltammograms in a potential window from -1.2 until $0.6 \mathrm{~V}$ versus SCE [16,21-25]. When the potential cycling is done in the range of -1.2 to $0.3 \mathrm{~V}$ or from -0.7 to $0.3 \mathrm{~V}$, no adsorption of the phthalocyanine or porphyrin occurs. Fig. 2 represents this phenomenon. Curve 1 is the 10th cyclic voltammogram of a bare gold electrode in a pH 12 buffer solution. Curve 2 represents the 50th cyclic voltammogram of a gold electrode in a $\mathrm{pH} 12$ buffer solution containing $1 \times 10^{-3} \mathrm{~mol} \mathrm{~L}^{-1}$ CoTCPor recorded in a potential window from -0.7 to $0.3 \mathrm{~V}$ versus SCE. No oxidation or reduction process occur in this potential range, which means that by excluding the $\alpha$-oxide formation no deposition takes 


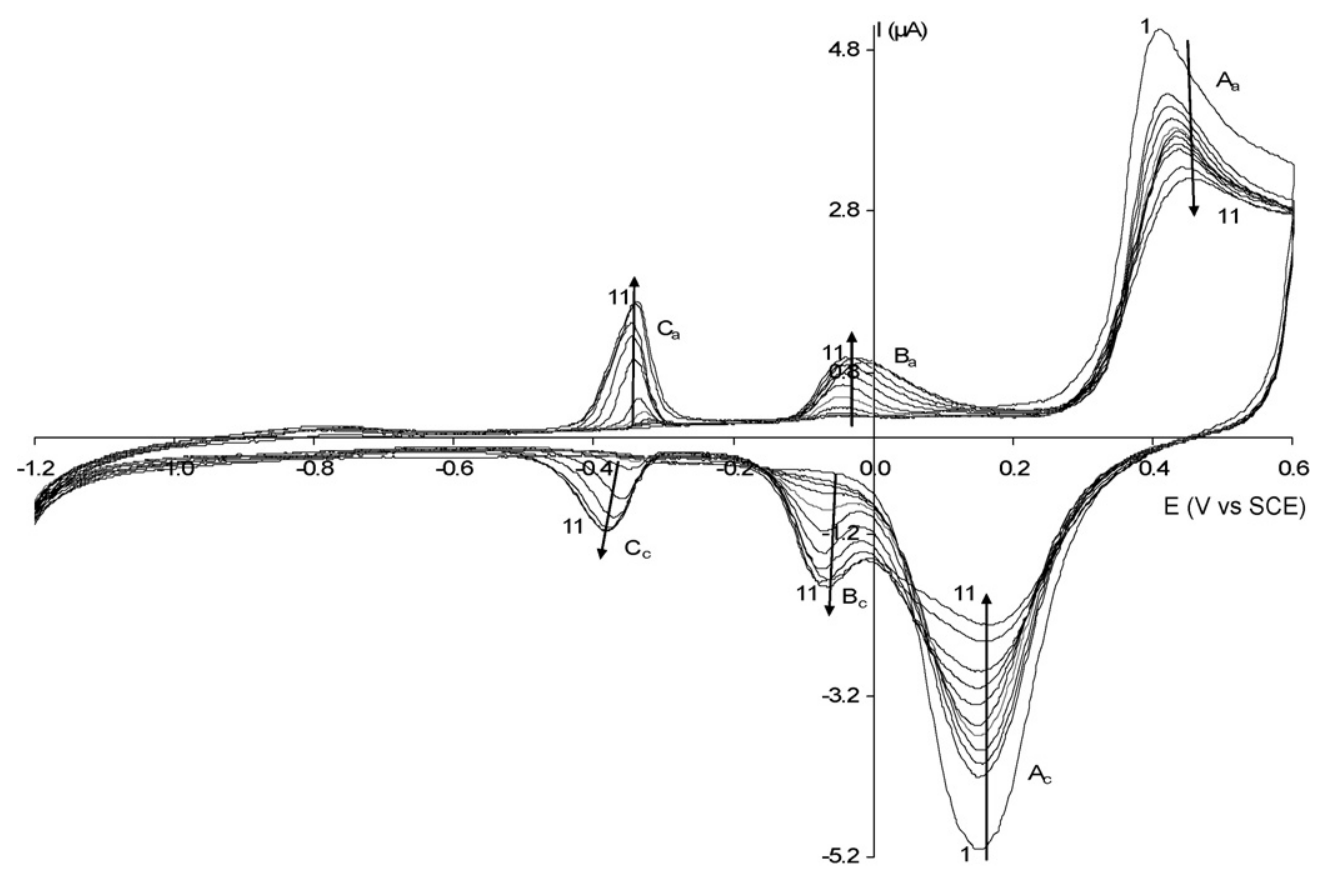

Fig. 1. Current-potential curves recorded at a gold electrode from -1.2 to $0.6 \mathrm{~V}$ in a $\mathrm{pH} 12$ buffer solution as a function of scan number. Scan numbers are (1) 10 , (2) 50, (3) 100, (4) 200, (5) 400, (6) 800, (7) 1600, (8) 2400, (9) 3200, (10) 4000 and (11) 5000.

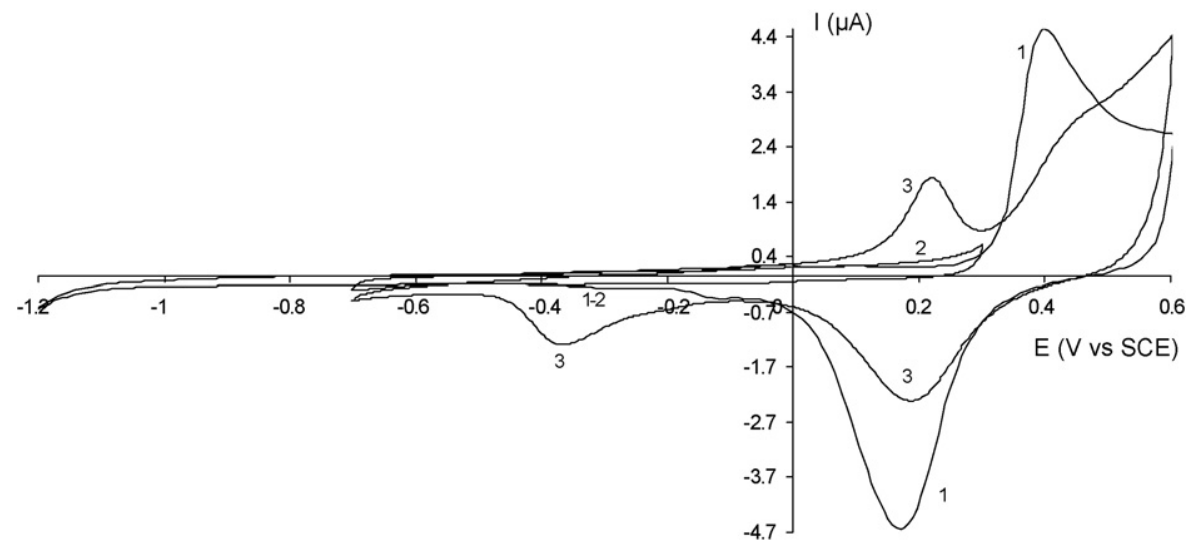

Fig. 2. Current-potential curve recorded at a gold electrode in a pH 12 buffer solution (curve 1) and the current-potential curve of a continuous cyclic scanning experiment in a $1.0 \times 10^{-3} \mathrm{~mol} \mathrm{~L}^{-1}$ CoTCPor solution in a potential window from -0.7 to $0.3 \mathrm{~V}$ (50th scan, curve 2 ) and -0.7 to $0.6 \mathrm{~V}$ (40th scan, curve 3 ).

place. Curve 3 is the 40th voltammetric scan of a gold electrode in a $1 \times 10^{-3} \mathrm{~mol} \mathrm{~L}^{-1}$ CoTCPor pH 12 buffer solution recorded from -0.7 to $0.6 \mathrm{~V}$ versus SCE. The peaks, corresponding to the oxidation of the gold surface (ca. $0.4 \mathrm{~V}$ versus $\mathrm{SCE}$ ) and the reduction of the gold oxide formed during surface oxidation (ca. $0.2 \mathrm{~V}$ versus SCE), are smaller when cycled in a CoTCPor solution. This is an indication for adsorption of CoTCPor onto the gold electrode, as covering the gold surface with CoTCPor prevents its oxidation and reduction. During the modification, the gold related redox reactions decrease as a function of scan number [21-24]. At 0.23 and $-0.38 \mathrm{~V}$ versus SCE, another oxidation and reduction peak is observed. These redox peaks can be attributed to the non-reversible reaction of adsorbed $\mathrm{Co}(\mathrm{III}) \mathrm{TCP}$ r/Co(II)TCPor $[17,24]$. Based on the above results, cycling through the potential region of surface roughening is needed to immobilize CoTCPor. Similar results were observed for CuTCPor. The 50th voltammetric scan of a gold electrode in a $1 \times 10^{-3} \mathrm{~mol} \mathrm{~L}^{-1} \mathrm{CuTCPor} \mathrm{pH} 12$ buffer solution recorded in a potential range from -0.7 to $0.3 \mathrm{~V}$ versus SCE is shown as curve 2 in Fig. 3. Only a very small redox couple at $-0.05 \mathrm{~V}$ versus SCE is observed indicating a small percentage of adsorption due to a certain roughness of the gold electrode. When the potential cycling is now done in an expanded region $(-1.2$ to $0.6 \mathrm{~V}$ versus $\mathrm{SCE}$ ), adsorption occurs resulting in a well defined redox couple around $-0.05 \mathrm{~V}$ versus SCE corresponding to the redox behaviour of the central metal ion (curve 3) [25].

Experimental evidence that the nature of the ring has no large effect on the redox properties of the central metal ion is given by Figs. 4 and 5. Curves 1-3 in Fig. 4 represent the oxidation and reduction peak of adsorbed $\mathrm{Co}(\mathrm{III}) / \mathrm{Co}$ (II) of a respectively CoTCPor, CoTSPor and CoTSPc modified gold electrode measured in a blank pH 12 buffer solution. The mod- 


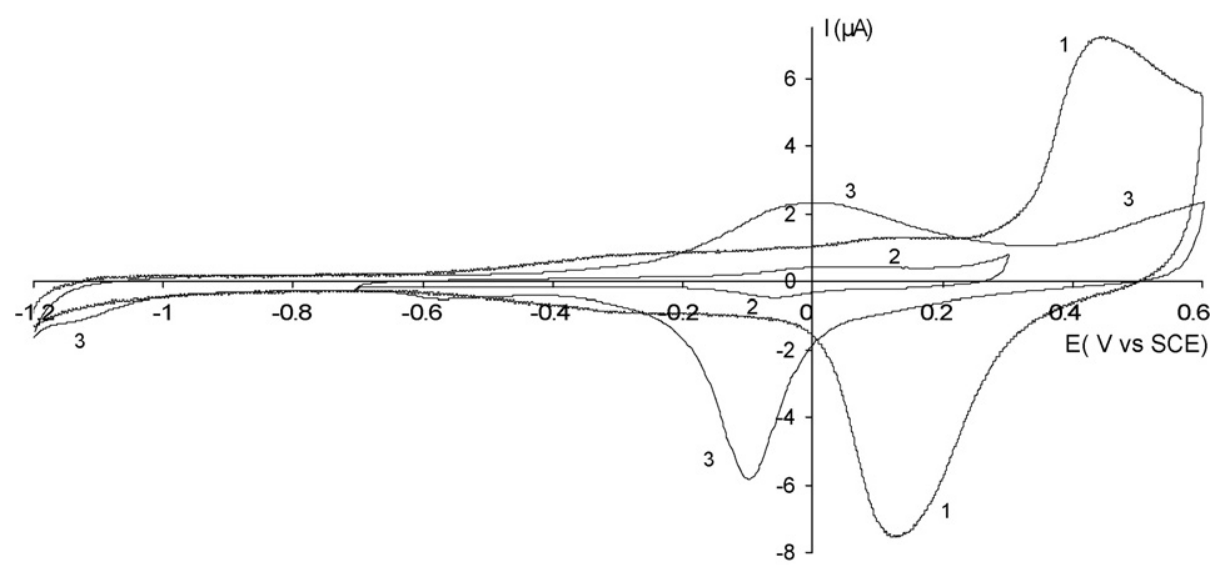

Fig. 3. Current-potential curve recorded at a gold electrode in a pH 12 buffer solution (curve 1) and the current-potential curve of a continuous cyclic scanning experiment in a $1.0 \times 10^{-3} \mathrm{~mol} \mathrm{~L}^{-1}$ CuTCPor solution in a potential window from -0.7 to $0.3 \mathrm{~V}$ (50th scan, curve 2 ) and -1.2 to $0.6 \mathrm{~V}$ ( 40 th scan, curve 3 ).

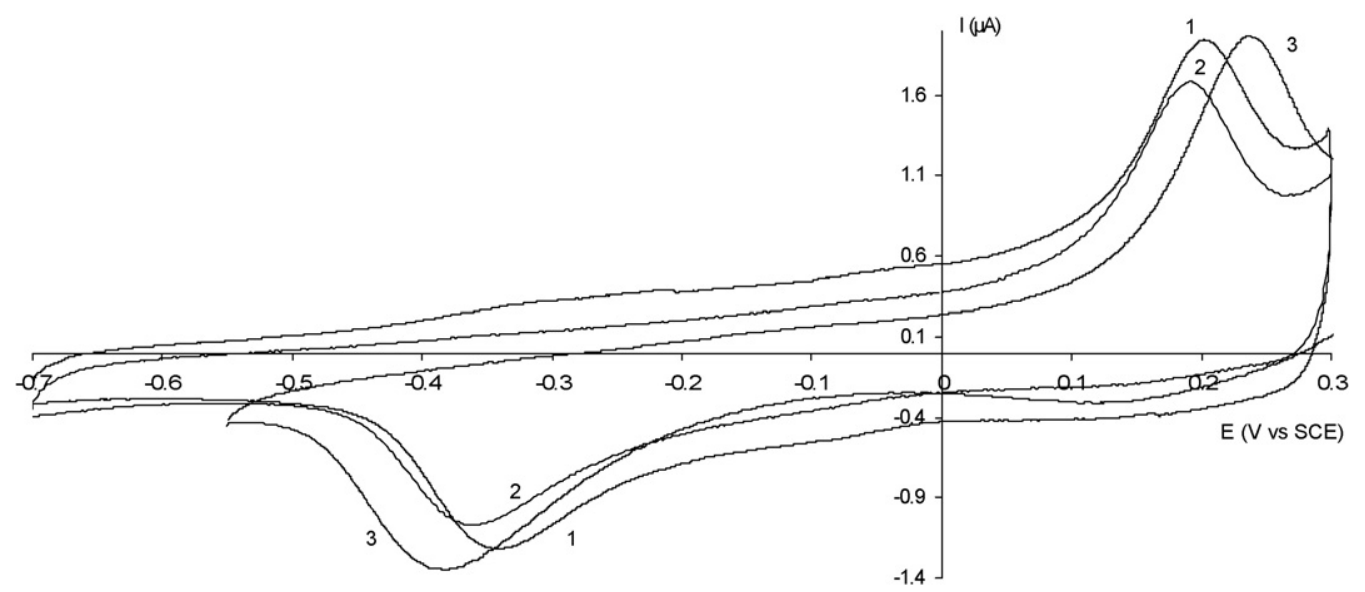

Fig. 4. Current-potential curves of a CoTCPor (1), CoTSPor (2) and CoTSPc (3) modified gold electrode in a pH 12 buffer solution.

ification was done by recording 60 cyclic voltammograms in a $1 \times 10^{-3} \mathrm{~mol} \mathrm{~L}^{-1}$ CoTCPor, CoTSPor or CoTSPc solution. Because of a small peak potential shift, it can be concluded that the Co ion placed in a porphyrin ring is more easily oxidized than Co in a phthalocyanine ring. A possible explanation for this phenomenon is that the diagonal distance between two nitrogen atoms is smaller for a phthalocyanine ring compared to a porphyrin ring $(\Delta=6 \mathrm{pm})$, which includes that electron transfer is more easily for a metal ion incorporated in a porphyrin structure [11]. For $\mathrm{Co}$, the influence of $\mathrm{N}$ atoms of the macrocyclic compound is likely not neglectible. In contrast, the influence of the nature of the substituents (C or S) on the redox behaviour of the central metal ion is neglectible. The electrochemical behaviour of a CuTCPor and CuTSPc modified gold

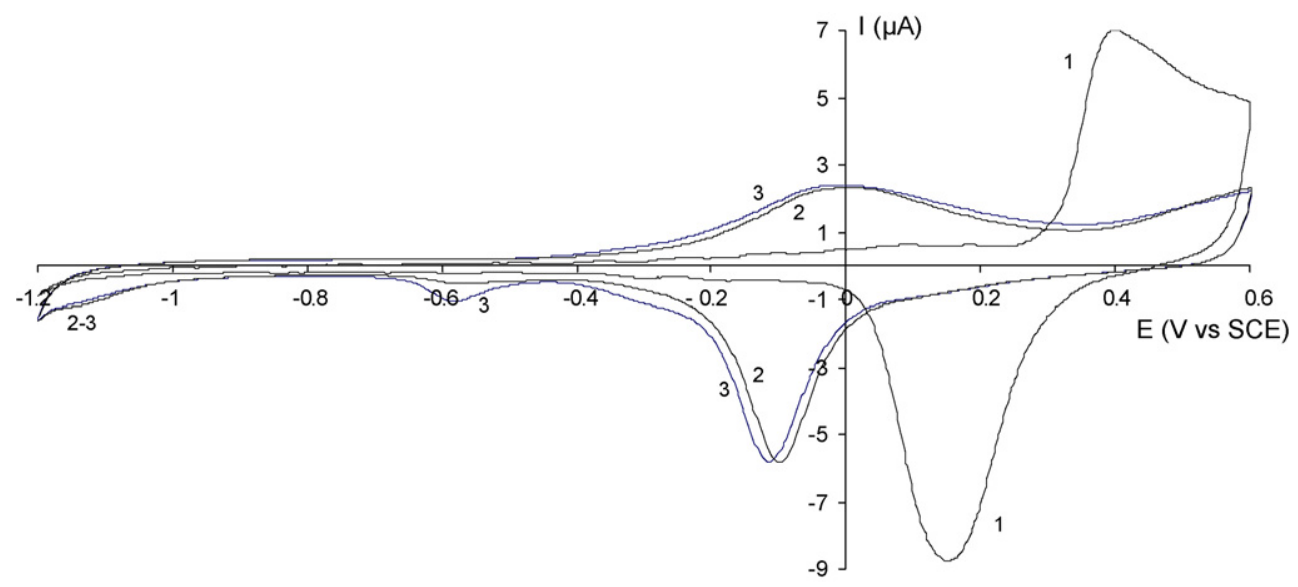

Fig. 5. Current-potential curves of a gold electrode (1) and a CuTCPor (2) and CuTSPc (3) modified gold electrode in a pH 12 buffer solution. 
electrode is shown in Fig. 5. Curve 1 is the 10th cyclic voltammogram of a blank gold electrode in a pH 12 buffer solution. Curve 2 and 3 represent the 5th cyclic voltammogram of a CuTCPor (2) and CuTSPc (3) modified gold electrode in a pH 12 buffer solution. The modification was done by recording 60 successive cyclic voltammograms in a $1 \times 10^{-3} \mathrm{~mol} \mathrm{~L}^{-1} \mathrm{CuTCPor}$ or CuT$\mathrm{SPc} \mathrm{pH} 12$ buffer solution in a potential window from -1.2 to $0.6 \mathrm{~V}$ versus SCE. Both curves 2 and 3 show the occurrence of the redox peaks of the central metal ion at around $-0.05 \mathrm{~V}$ versus SCE. In contrast with Co, there is no clear difference between the electrochemical behaviour of the porphyrin and phthalocyanine derivative. Therefore, it is suggested that for copper there is no fundamental interference of neighbouring atoms. Probably, the four-coordination state of copper, compared to the six coordination of cobalt, prevents the central metal ion for any major interference with surrounding atoms or ligands. Secondly, a copper ion incorporated in a phthalocyanine or porphyrin is also characterized by the longest $\mathrm{N}_{\alpha}-\mathrm{M}-\mathrm{N}_{\alpha}$ distance (3.9353 $\AA$ ) and a small ring contraction of only $3.75^{\circ}$. The contraction and thus influence of neighbouring atoms is increasing in the order $\mathrm{Cu}$ (II) $<\mathrm{Fe}$ (III) $<\mathrm{Co}$ (II) [22].

The immobilization of phthalocyanines and porphyrins onto gold electrodes only starts when surface roughening occurs, when reactive adatoms are created. In addition, the potential of the adsorption processes of the cobalt and copper ion are identical to the redox potentials of the gold adatoms. Therefore, it is suggested that the intervention of adatom species is a necessity for the immobilization of phthalocyanines and porphyrins. In the case of cobalt ion macromolecules, regardless the nature of the ring, the adsorption reduction process takes place at $-0.38 \mathrm{~V}$ versus SCE, identical to the reduction potential of gold hydrous oxides formed out of the most reactive adatoms. Due to the non-reversibility of the $\mathrm{Co}$ (III)ads/Co(II)ads redox couple, the intervening species for the oxidation can differ from the ones for the reduction reaction. Here, the oxidation of $\mathrm{Co}(\mathrm{II}) \mathrm{ads}$ takes place on bare gold and is not electrocatalyzed by adatoms or hydrous oxides. For copper ion macromolecules, the redox potential of the oxidation and reduction of the adsorbed copper compound equals the potential of the redox process of the less active gold adatoms. In both redox processes, the intervention of adatoms or hydrous oxides takes place. The most reactive adatoms prefer a reaction or deposition of cobalt macrocycles, the less reactive prefer an immobilization of copper macrocycles. A hypothesis for this phenomenon can again be found in the coordination state of the central metal ion. The cobalt ion complexes are characterized by a six coordination state with the existence of axial ligands, which can act as a bridge, and making the phthalocyanines or porphyrins more easily accessible to the reactive species onto the gold electrode. So, the most reactive species will favour the most accessible compounds (less steric hinder), more specific the Co ones. Because copper ion complexes do not have axial ligands, the deposition of these compounds onto surface defects will take more energy and will thus take place at higher potentials.

\subsection{Electrocatalytic property towards hydroxide}

A CoTCPor modified gold electrode is selected to investigate its electrocatalytic behaviour towards hydroxide in a $0.1 \mathrm{~mol} \mathrm{~L}^{-1}$ $\mathrm{Na}_{2} \mathrm{SO}_{4}$ solution by adding successive amounts of $\mathrm{NaOH}$. As the electrochemical deposition of CoTCPor at a gold electrode was done in a $\mathrm{pH} 12$ buffer solution, the stability of the modified electrode was first tested in $0.1 \mathrm{~mol} \mathrm{~L}^{-1} \mathrm{Na}_{2} \mathrm{SO}_{4}$ (pH 6.8) as shown in Fig. 6. Curve 1 represents the current-potential behaviour of a CoTCPor modified electrode in a $\mathrm{pH} 12$ buffer solution. The peaks relevant for this study are $D_{\mathrm{a}}$ and $D_{\mathrm{c}}$ which correspond to the $\mathrm{Co}(\mathrm{III}) \mathrm{TCPor}_{\mathrm{ads}} / \mathrm{Co}(\mathrm{II}) \mathrm{TCPor}_{\mathrm{ads}}$ redox process $[17,24]$. The other peaks can be explained as redox processes of gold adatoms. When bringing the CoTCPor modified electrode in a $0.1 \mathrm{~mol} \mathrm{~L}^{-1} \mathrm{Na}_{2} \mathrm{SO}_{4}$ solution, the potential of the $\mathrm{Co}$ (III)TCPor $\mathrm{ads}_{\mathrm{s}} / \mathrm{Co}$ (II)TCPor $\mathrm{Tds}_{\mathrm{ads}}$ redox process shifts towards a more positive value (curve 2 ). The potential of the oxidation $\left(D_{\mathrm{a}}^{\prime}\right)$ and reduction $\left(D_{\mathrm{c}}^{\prime}\right)$ peak is respectively 0.39 and $-0.22 \mathrm{~V}$ versus SCE. Curve 3 (pH 12) is recorded after curve 2 and a serial of experiments in a $0.1 \mathrm{~mol} \mathrm{~L}^{-1} \mathrm{Na}_{2} \mathrm{SO}_{4}$ solution. A regeneration of processes $D_{\mathrm{a}}$ and $D_{\mathrm{c}}$ is observed. Compared to curve 1 , the charges of both processes regain their original values. Based on these results, it can be stated that the CoTCPor modified elec-

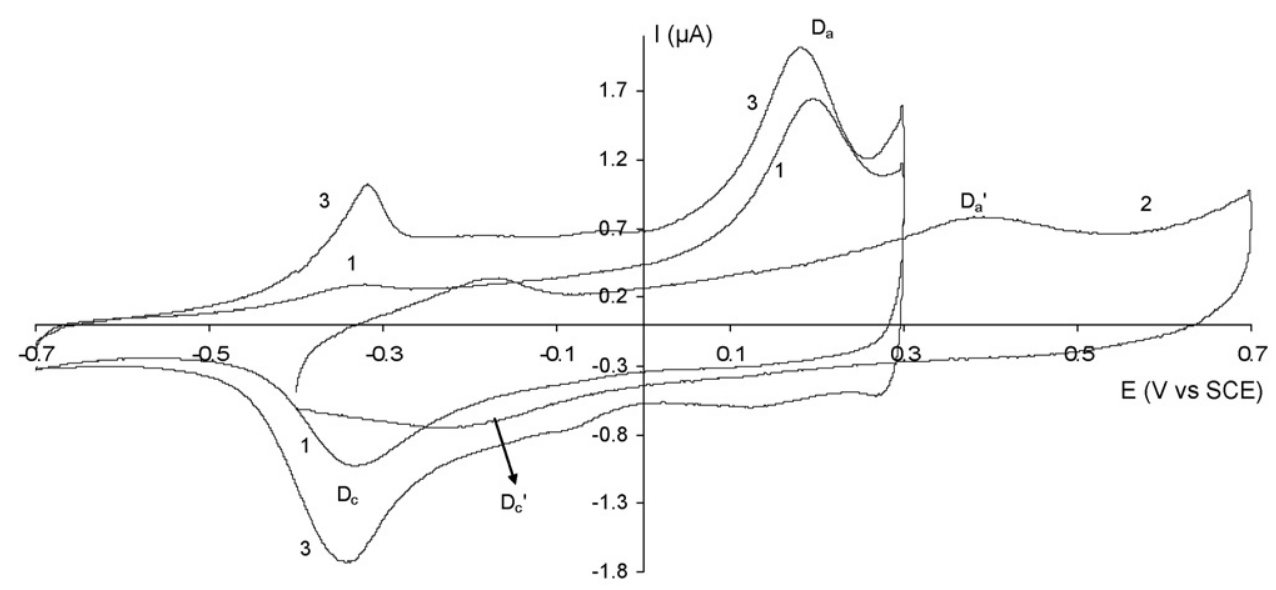

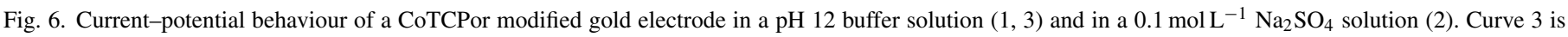
recorded after curve 2 (after contact with a $\mathrm{Na}_{2} \mathrm{SO}_{4}$ solution). 


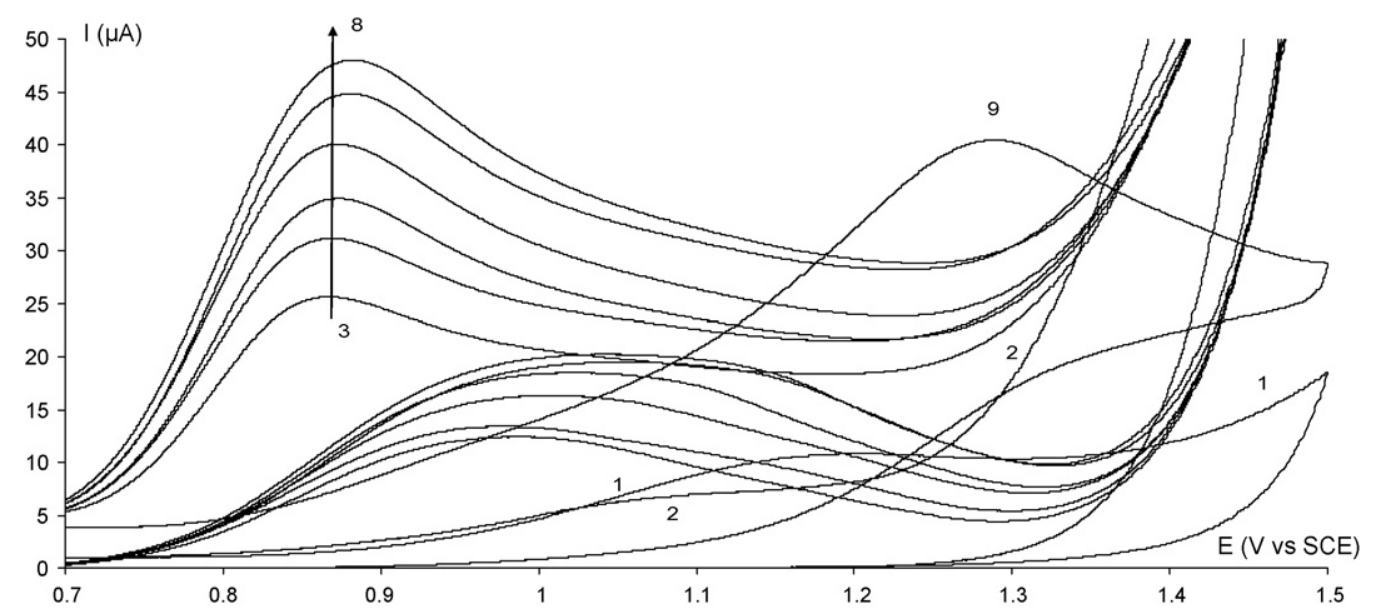

Fig. 7. Cyclic voltammograms of a gold electrode (1) and a CoTCPor modified gold electrode (2) in a $0.1 \mathrm{~mol} \mathrm{~L}^{-1} \mathrm{Na}_{2} \mathrm{SO}_{4}$ solution containing several sodium hydroxide concentrations: 2.30 (3), 2.89 (4), 3.47 (5), $4.03(6), 4.58(7), 5.11(8-9) \times 10^{-3} \mathrm{~mol} \mathrm{~L}^{-1} \mathrm{NaOH}$. Curves $2-8$ are measured at a modified electrode, curve 9 at a bare gold electrode.

trode (modification done in $\mathrm{pH} 12$ buffer solution) is stable in a $0.1 \mathrm{~mol} \mathrm{~L}^{-1} \mathrm{Na}_{2} \mathrm{SO}_{4}$ solution. The reactivity of the modified electrode towards hydroxide is the next topic under study.

Fig. 7 shows cyclic voltammograms of a bare gold (curve 1) and a CoTCPor modified gold electrode (curve 2) in a $0.1 \mathrm{~mol} \mathrm{~L}^{-1} \mathrm{Na}_{2} \mathrm{SO}_{4}$ solution containing several hydroxide concentrations over the range of $2.3-5.12 \times 10^{-3} \mathrm{~mol} \mathrm{~L}^{-1}$ (curves 3-9). The oxidation processes with a peak potential of ca. 0.87 and $1.29 \mathrm{~V}$ versus SCE are attributed to the oxidation of hydroxide with formation of oxygen at respectively a modified (3-8) and an unmodified gold electrode (9). The half-wave potential for this oxidation is $0.79 \mathrm{~V}$ versus SCE. Several observations indicate electrocatalytic behaviour towards hydroxide. First, the voltammetric waves are shifted towards less positive potentials (ca. $420 \mathrm{mV}$ ) in the case of the modified electrode. This means that less overpotential should be applied to the system because of the presence of CoTCPor that provides an alternative, less energy demanding, oxidation reaction path for hydroxide. Secondly, the shape of the voltammetric wave is better defined (more peak shaped wave) and the peak currents are higher compared to the peak current obtained at an unmodified electrode. Thirdly, the slope of the inclining part of the wave is higher at the CoTCPor modified electrodes, revealing faster charge transfer kinetics.

Electrocatalysing the oxidation of hydroxide has advantageous consequences for its analytical application, especially in sensor development to monitor the hydroxide concentration during processing. A calibration curve could be obtained at a CoTCPor modified gold electrode, with a sensitivity of $8.4 \pm 0.3 \mu \mathrm{Ammol} \mathrm{L}-1$. The peak current of the calibration plot is the net peak current, obtained by subtracting the background current from the experimental peak current. Note that this background current is stable and independent on the hydroxide concentration (see Fig. 7), which is not the case for the unmodified electrode (not shown).

Taking into account the criterion that the detection limit corresponds to twice the standard deviation of the blank divided by the sensitivity, this results in a detection limit of $11 \times 10^{-6} \mathrm{~mol} \mathrm{~L}^{-1}$ for a CoTCPor modified gold electrode. Published values for the detection limit of hydroxide at other electrodes, such as micro electrodes, vary in the range of $0.1-1 \times 10^{-3} \mathrm{~mol} \mathrm{~L}^{-1}[26,27]$. A detection limit for the unmodified electrode was more difficult to obtain due to the irreproducible background current and broad oxidation peak. At the potential at which the hydroxide oxidation is observed at an unmodified electrode, gold(III) and $\beta$-oxides are formed which alter the electron transfer resulting in an extended oxidation wave. From $2.1 \times 10^{-3} \mathrm{~mol} \mathrm{~L}^{-1}$ hydroxide, the cyclic voltammogram differs from the background. Compared to the later value, the detection limit calculated at a CoTCPor modified electrode is much better.

\section{Conclusions}

This paper shows that surface roughening by potential cycling through the $\alpha$-oxide formation ( $0.3-0.6 \mathrm{~V}$ versus SCE) is needed to immobilize different phthalocyanines or porphyrins onto gold electrodes. It is suggested that the intervention of adatoms is a necessity for electrodeposition. The potential of the adsorption processes of the cobalt and copper ion are identical to the redox potentials of some gold adatoms. The most reactive adatoms prefer a deposition of cobalt macrocycles, the less reactive copper compounds. The nature of the ring has no large effect on the redox properties of the central metal ion. A hypothesis for this phenomenon is found in the coordination state of the central metal ion.

It is also observed that a CoTCPor modified gold electrode shows electrocatalytic behaviour towards hydroxide in a $0.1 \mathrm{~mol} \mathrm{~L}^{-1} \mathrm{Na}_{2} \mathrm{SO}_{4}$ solution. A calibration curve could be obtained and a detection limit of $11 \times 10^{-6} \mathrm{~mol} \mathrm{~L}^{-1}$ is found.

\section{References}

[1] H.H. Liebermann, Rapidly Solidified Alloys, New York, Marcel Dekker, 1993 (Chapter 3).

[2] C. Suryanarayana, Materials Science and Technology, VCH, Weinheim, 1991, pp. 57-110.

[3] J.O'M. Bockris, S.U.M. Khan, Surface Electrochemistry: A Molecular Level Approach, Plenum Press, New York, 1993, pp. 323-330. 
[4] L.D. Burke, A.J. Ahern, A.P. O’Mullane, Gold Bull. 35 (2002) 3-10.

[5] L.D. Burke, L.M. Hurley, J. Solid State Electrochem. 6 (2002) 101-110.

[6] K. Juodkazis, J. Juodkazyte, T. Juodiene, A. Lukinskas, J. Electroanal. Chem. 441 (1998) 19-24.

[7] L.D. Burke, J.F. O’Sullivan, Electrochim. Acta 37 (1992) 585-594.

[8] L.D. Burke, W.A. O'Leary, J. Appl. Electrochem. 19 (1989) 758-767.

[9] P.I. Iotov, S.V. Kalcheva, Bull. Electrochem. 16 (2000) 407-414.

[10] L.D. Burke, A.P. O'Mullane, J. Solid State Electrochem. 4 (2000) 285-297.

[11] C.C. Leznoff, A.B.P. Lever, Phthalocyanines Properties and Applications, vol. 3, VCH Publishers, Weinheim, 1993, p. 1.

[12] A.B.P. Lever, Chemtech 17 (1987) 506-510.

[13] M. Kato, Y. Nishioka, K. Kaifu, K. Kawamura, S. Ohno, Appl. Chem. Lett. 86 (1985) 196-197.

[14] T.A. Temofonte, K.F. Schoch, J. Appl. Chem. 65 (1989) 1350-1355.

[15] K.M. Kadish, K.M. Smith, R. Guilard, The Porphyrin Handbook, vol. 3, Academic Press, 2000 (Chapter 21).

[16] K. De Wael, P. Westbroek, E. Temmerman, Electroanalysis 17 (2005) 263-268.

[17] K. Peeters, K. De Wael, L. Vincze, A. Adriaens, Anal. Chem. 77 (2005) $5512-5519$.
[18] R. Woods, Electroanalytical Chemistry, vol. 9, Marcel Dekker, New York, 1976, pp. 1-162.

[19] R.S. Sirohi, M.A. Gensham, J. Electrochem. Soc. 116 (1969) 910.

[20] L.D. Burke, M.E.G. Lyons, Modern Aspects of Electrochemistry, vol. 18, Plenum Press, New York, 1986, pp. 169-248.

[21] K. De Wael, P. Westbroek, E. Temmerman, J. Electroanal. Chem. 567 (2004) 167-173.

[22] K. De Wael, P. Westbroek, P. Bultinck, D. Depla, P. Vandenabeele, A. Adriaens, E. Temmerman, Electrochem. Commun. 7 (2005) 87-96.

[23] K. De Wael, P. Westbroek, A. Adriaens, E. Temmerman, Electrochem. Solid-State Lett. 8 (2005) C65-C68.

[24] K. De Wael, P. Westbroek, A. Adriaens, E. Temmerman, Electrochim. Acta 50 (2005) 4269-4274.

[25] K. De Wael, K. Peeters, D. Bogaert, H. Buschop, L. Vincze, A. Adriaens, J. Electroanal. Chem. 603 (2007) 212-218.

[26] M.E. Abdelsalam, G. Denuault, M.A. Baldo, C. Bragato, S. Daniele, Electroanalysis 13 (2001) 289-294.

[27] O. Ordeig, C.E. Banks, T.J. Davies, F.J. del Campo, F.X. Munoz, R.G. Compton, Anal. Sci. 22 (2006) 679-683. 